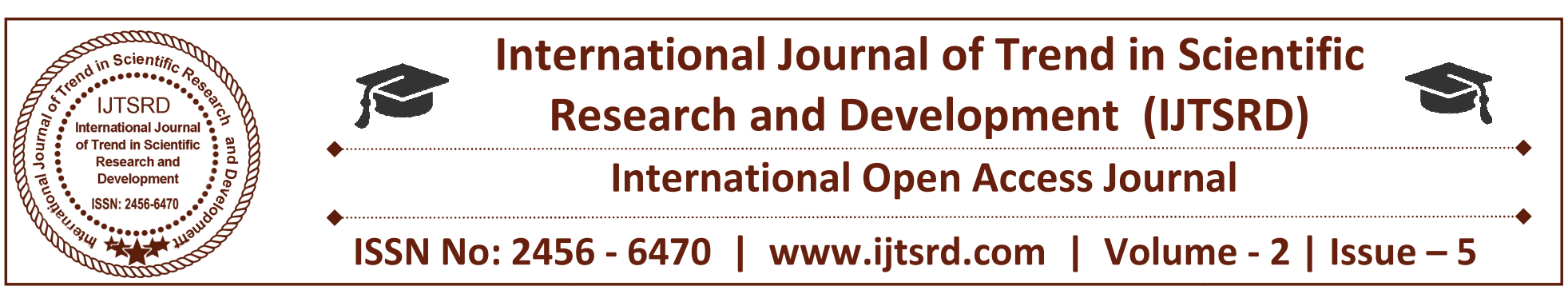

\title{
The Shunt Active Power Filter to Compensate Reactive Power and Harmonics with Optimized Pi Controller in a 3 Phase 3 Wire Distribution System
}

\author{
Mr. Amit Kumar Rajan ${ }^{1}$, Dr. E Vijay Kumar ${ }^{2}$ \\ ${ }^{1}$ M.Tech. Scholar, ${ }^{2}$ Head of Electrical \& Electronics Engineering \\ RKDF Institute of Science \& Technology, Sarvepalli Radhakrishnan University, \\ Bhopal, Madhya Pradesh, India
}

\begin{abstract}
In this paper is to study the denomination Power quality and large refers to maintaining a proximal sinusoidal power distribution bus voltage at rated magnitude and frequency. This is mainly affected by the generation of harmonics. Even though electronic and non-linear devices are flexible, economical and energy efficient, they may degrade power quality by creating harmonic currents and consuming excessive reactive power.
\end{abstract}

This paper shows the method of improving the power quality using shunt active power filter with proposed optimized PI. The proposed topic comprises of PI controller, filter hysteresis current control loop, dc link capacitor. The switching signal generation for filter is from hysteresis current controller techniques. With the all these element shunt active power filter reduce the total harmonic distortion. Its source current, compensating current and THD values are studied, then PI control strategy is applied then the differences in THD are compared. The PI feedback compensation design starts with the small signal system's transfer function. Then an optimum constant of PI for a Shunt-APF is proposed and implemented to enhance its response to compensation of harmonics of linear and non-linear loads. The obtained results have demonstrated the ability to compensate the current harmonics effectively under distorted source conditions. The fluctuation in the dc bus voltage of the filter depends on the compensation speed of the outer loop that regulates the dc bus voltage.
The proposed shunt active filter model uses balanced linear and non-linear load works successfully lowers the THD within IEEE norms and satisfactorily works to compensate current harmonics. The model is made in MATLAB / SIMULINK and successfully reduces the harmonic in the source current.

Keywords: Active Power Filter, threshold harmonics distortions, quality factor, transfer Function, hysteresis etc.

\section{INTRODUCTION}

In these papers gives the overview of the work. This comprises of a brief description of power quality, harmonic sources and effects followed by literature survey. The objectives and organization of the thesis are mentioned in this paper.

The PQ issue is defined as "any occurrence manifested in voltage, current, or frequency deviations that results in damage, upset, failure, or miss-operation of end-use equipment." Almost all PQ issues are closely related with PE in almost every as pect of commercial, domestic, and industrial application. Equipment using power electronic devise are residential appliances like TVs, PCs etc. business and office equipment like copiers, printers etc. industrial equipment like programmable logic controllers (PLCs), adjustable speed drives (ASDs), rectifiers, inverters, CNC tools and so on. The Power Quality (PQ) problem can be detected from one of the following several symptoms depending on the type of issue involved. 


\section{HARMONIC POWER FILTERS}

The steady increase in non-linear loads on the power supply network raises question about power quality and reliability. The challenge is knowing how to select and deploy harmonic filters correctly to achieve satisfactory performance. In this chapter we discuss about different non-linear loads and what kind of filters must be used to effectively mitigate harmonics in the system.

\subsection{Current source non-linear load}

Thyristor converters are a common and typical source of harmonic currents. Fig. 2.1(a) shows a thyristor rectifier where a sufficient dc inductance produces a dc current. Therefore, it is called a current-source nonlinear load and represented as a current source shown in Fig. 2.1(b). Similarly, diode rectifiers with a sufficient dc inductance, a highly inductive load with silicon-controlled rectifier (SCR) ac power control, etc., are current-source nonlinear loads.

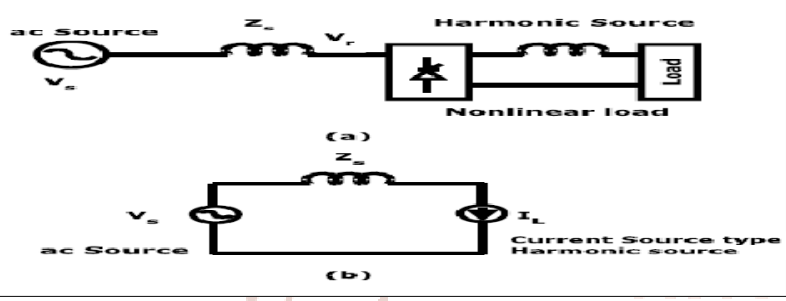

Figure 2.1: Typical CSNL

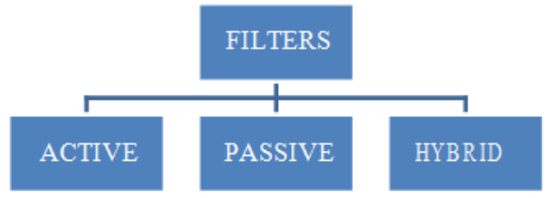

Figure 2.3: Types of power filters

\section{SHUNT ACTIVE POWER FILTER}

The shunt-connected active power filter, with a selfcontrolled dc bus, has a topology similar to that of a static compensator (STATCOM) used for reactive power compensation in power transmission systems. Shunt active power filters compensate load current harmonics by injecting equal-but opposite harmonic compensating current. In this case the shunt active power filter operates as a current source injecting the harmonic components generated by the load but phase-shifted by $180^{\circ}$.

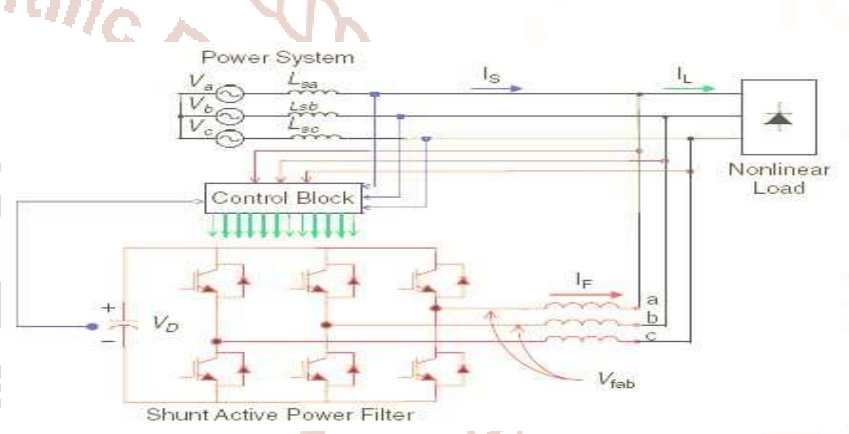

Figure.3.1. Shunt active power filter topology

\subsection{Voltage source non-linear load}

Another common type of harmonic source is a diode rectifier with smoothing dc capacitors, as shown in Fig. 2.2(a). Therefore, the diode rectifiers behave like a voltage source, rather than a current source. Fig. 2.2(b) shows the equivalent circuit of the diode rectifier system where the diode rectifier is represented as a harmonic voltage source or voltagesource nonlinear load.

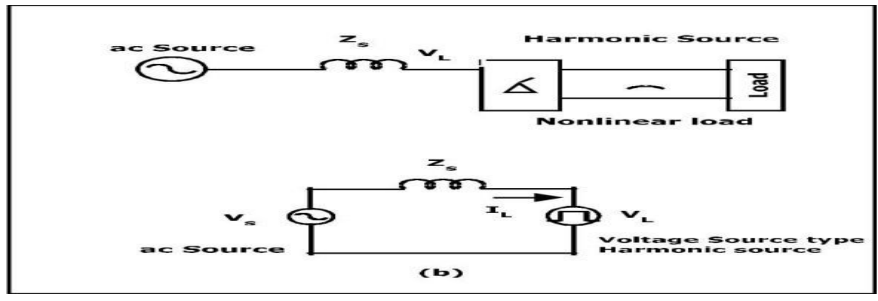

Figure 2.2: Typical VSNL

\subsection{Types of power filter}

There are different types of power filter [7]; analyzing the current situation power filters widely classified into three categories, Fig 2.3 shows these categories of power filters
Figure 3.1 shows the connection of a shunt active power filter and Figure 3.2shows how the active filter works to compensate the load harmonic currents.

\section{PI CONTROL SCHEME}

$>$ De voltage control loop

$>$ Transfer function of PWM converter

$>$ Selection of PI controller parameters

The complete schematic diagram of the shunt active power filter is shown in figure 4.1. While figure 4.2.gives the control scheme realization. The actual capacitor voltage is compared with a set reference value. 


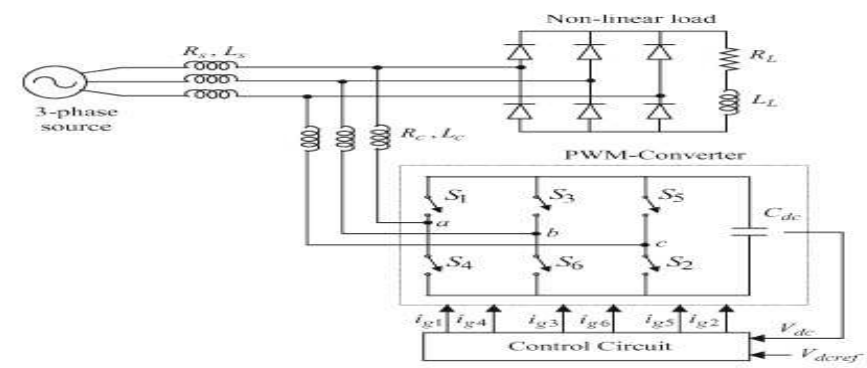

Figure.4.1. Schematic diagram of shunt active filter

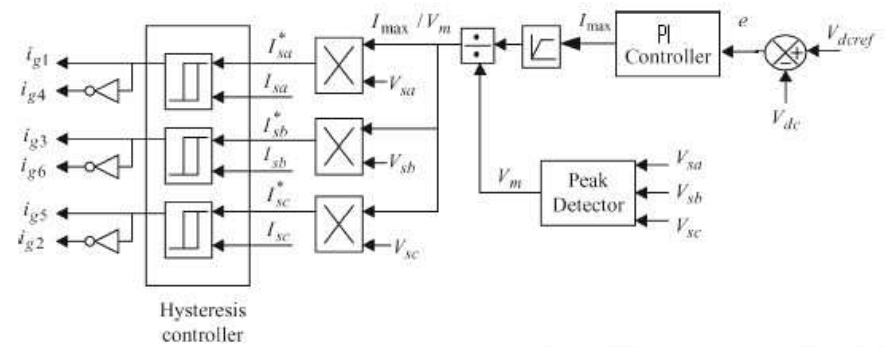

Figure4.2. APF Control scheme with PI controller

The error signal is fed to PI controller. The output of PI controller has been considered as peak value of the Reference current, It is further multiplied by the unit sine vectors (usa, usb, and usc) in phase with the source voltages to obtain the reference currents (isa*, isb*, and isc*). These reference currents and actual currents are given to a hysteresis based, carrier less PWM current controller to generate switching signals of the PWM converter [2]. The difference of reference current template and actual current decides the operation of switches. To increase current of particular phase, the lower switch of the PWM converter of that particular phase is switched on, while to decrease the current the upper switch of the particular phase is switched on. These switching signals after proper isolation and amplification are given to the switching devices. Due to these switching actions current flows through the filter inductor Lc, to compensate the harmonic current and reactive power of the load, so that only active power drawn from the source.

\section{SIMULATION MODELS AND RESULTS ANALYSIS}

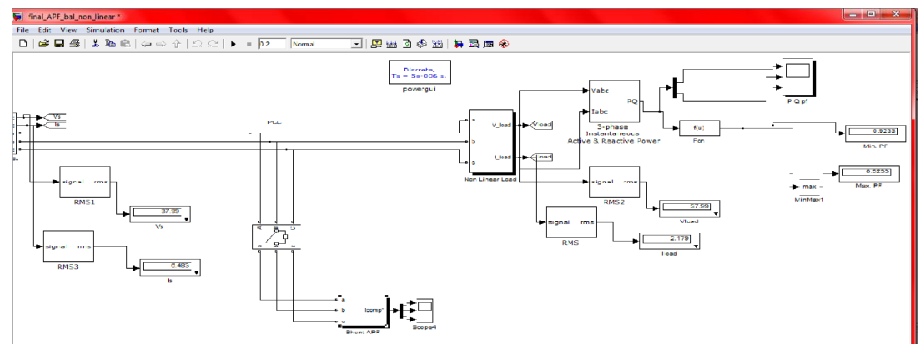

Figure 5.1.230 PI constant balanced load R

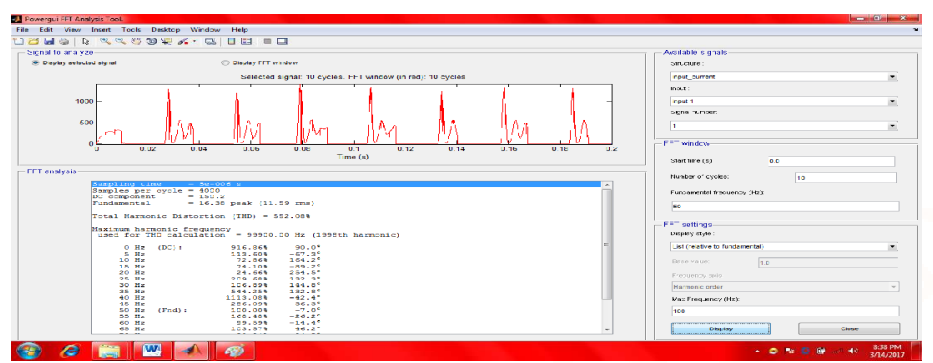

Figure 5.2 THD value for 230 PI constant balanced load $\mathrm{R}$

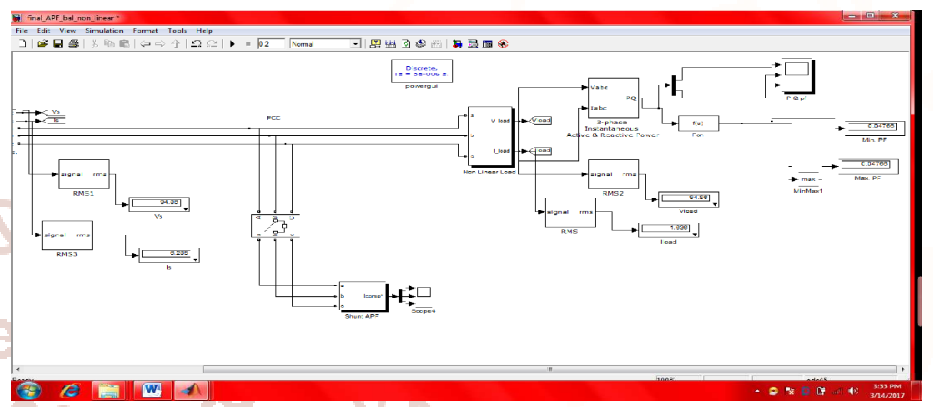

Figure 5.3 For 250 PI constant unbalanced load RC

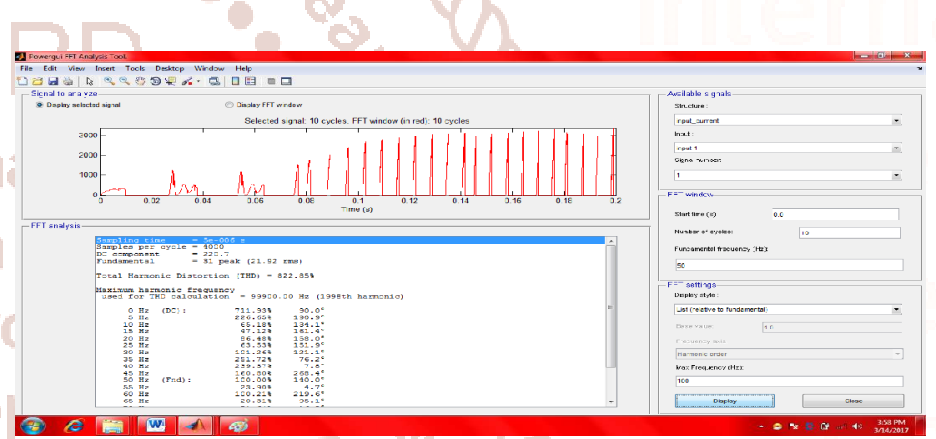

Figure 5.4 THD value for 250 PI constant Unbalanced load RC

\section{RESULTS}

Table-1 Observed results for balanced load:

\begin{tabular}{|c|c|c|}
\hline Sr. no & Parameter & Obtained results \\
\hline 1 & Source voltage (Vs) & $45.99 \mathrm{~V}$ \\
\hline 2 & Source current ( Is) & $4.55 \mathrm{~A}$ \\
\hline 3 & Load voltage $(\mathrm{V}$ load) & $45.99 \mathrm{~V}$ \\
\hline 4 & Load current $(\mathrm{I}$ load) & $1.972 \mathrm{~A}$ \\
\hline 5 & Power factor $(\mathrm{PF})$ & 0.9968 \\
\hline
\end{tabular}

Table-2 Observed results for Un-balanced load:

\begin{tabular}{|c|c|c|}
\hline Sr. no & Parameter & Obtained results \\
\hline 1 & Source voltage (Vs) & $18.61 \mathrm{~V}$ \\
\hline 2 & Source current ( Is) & $5.79 \mathrm{~V}$ \\
\hline 3 & Load voltage (V load) & $18.61 \mathrm{~V}$ \\
\hline 4 & Load current (I load) & $3.04 \mathrm{~A}$ \\
\hline 5 & Power factor (PF) & 0.995 \\
\hline
\end{tabular}


International Journal of Trend in Scientific Research and Development (IJTSRD) ISSN: 2456-6470

Table-3 Result of Balanced load for different PI constant

\begin{tabular}{|c|c|c|c|c|c|c|}
\hline $\begin{array}{c}\text { PI } \\
\text { constant }\end{array}$ & VS & IS & VL & IL & P.F & THD \\
\hline 150 & 10.4 & 7.4 & 54.4 & 2.55 & 1 & $3.14 \%$ \\
\hline 170 & 51.85 & 5.88 & 51.85 & 1.45 & 0.93 & $3.16 \%$ \\
\hline 190 & 43.55 & 6.5 & 43.55 & 2.4 & 0.92 & $3.70 \%$ \\
\hline 210 & 35.9 & 6.8 & 35.9 & 2.03 & 0.90 & $2.35 \%$ \\
\hline 230 & 37.99 & 6.48 & 37.99 & 2.17 & 0.92 & $5.53 \%$ \\
\hline 250 & 91.91 & 6.0 & 91.91 & 1.85 & $\begin{array}{c}- \\
0.57\end{array}$ & $8.60 \%$ \\
\hline
\end{tabular}

Table-4 Result of Unbalanced RC load for different PI constant.

\begin{tabular}{|c|c|c|c|c|c|c|}
\hline $\begin{array}{c}\text { PI } \\
\text { constant }\end{array}$ & VS & IS & VL & IL & P.F & THID \\
\hline 150 & 10.4 & 7.4 & 10.4 & 1.9 & 0.93 & $2.70 \%$ \\
\hline 170 & 10.4 & 7.4 & 10.4 & 1.9 & 0.90 & $2.65 \%$ \\
\hline 190 & 43.5 & 6.5 & 43.5 & 2.4 & 0.92 & $3.70 \%$ \\
\hline 210 & 35.9 & 6.8 & 35.9 & 2.0 & 0.98 & $2.31 \%$ \\
\hline 230 & 78.8 & 6.1 & 78.8 & 1.6 & 0.80 & $4.39 \&$ \\
\hline 250 & 94.8 & 6.2 & 94.86 & 1.6 & 0.047 & $8.22 \%$ \\
\hline
\end{tabular}

\section{CONCLUSION}

Presence of constant instantaneous active power is due to the positive sequence current and only in case of purely resistive loan but may be unbalance.

The presence of constant instantaneous imaginary power is due to the positive sequence current and only in the case of pure inductive load but may be unbalance

The presence of oscillations in both of instantaneous powers is due to the negative sequence current whether a load is purely resistive or inductive From FFT analysis and table 1 to 4 seems that the proposed shunt-APF system with optimized PI system along constant 210 outperform for balanced and unbalanced configuration load (R,RC,RL and RLC) for unique power factor.

\section{REFERENCES}

1. H. Akagi "New trends in active filters for power conditioning, "IEEE Trans. Ind. Appl., Vol. 32, No. 6,pp. 1312-1322, Nov./Dec.1996.

2. F. Z. Peng, G. W. Ott Jr., D. J. Adams, "Harmonic and reactive power compensation based on the generalized instantaneous reactive power theory for three-phase four-wire systems" IEEE Trans. Power Electron., Vol. 13, No. 5, Nov. 1998.

3. M. I. M Montero, E. R. Cadaval, and F. B. Gonzalez, "Comparison of control strategies for shunt active power filters in three-phase four-wire systems," IEEE Trans. Power Electron., Vol. 22, No. 1, Jan. 2007.

4. W. M. Grady, M. J. Samotyj, and A. H. Noyola, "Survey of active power line conditioning methodologies," IEEE Transactions on Power Delivery, vol. 5, no. 3, Jul. 1990, pp. 1536-1542.

5. H. Akagi, Y. Kanazawa, and A. Nabae, "Instantaneous reactive power compensators comprising switching devices without energy storage components," IEEE Transactions on Industry Applications, vol. IA-20, no. 3, May/Jun. 1984, pp. 625-630.

6. S. Jain, P. Agarwal, and H. O. Gupta, "Design simulation and experimental investigations on a shunt active power filter for harmonics and reactive power compensation," Electrical Power Components and Systems, vol. 32, no. 7, Jul. 2003, pp. 671-692.

7. F. Z. Peng, H. Akagi, and A. Nabae, "Study of active power filters using quad series voltage source PWM converters for harmonic compensation," IEEE Transactions on Power Electronics, vol. 5, no. 1, Jan. 1990, pp. 9-15.

8. H. Akagi, "Trends in active power line conditioners," IEEE Transactions on power Electronics, vol 9, no 3, 1994, pp 263-268.

9. S. K. Jain, P. Agrawal, and H. O. Gupta, "Fuzzy logic controlled shunt active power filter for power quality improvement," Proceedings of Institute of Electrical Engineers, Electrical Power Applications, vol. 149, no. 5, 2002.

10. L. A. Morgan, J. W. Dixon \& R. R. Wallace, "A three phase active power filter operating with fixed switching frequency for reactive power and current harmonics compensation," IEEE Transactions on Industrial Electronics, vol.42, no.4, August 1995, pp 402-408.

11. H. Akagi "New trends in active filters for power conditioning," IEEE Trans. Ind. Appl., Vol. 32, No. 6, pp. 1312-1322, Nov./Dec.1996.

12. F. Z. Peng, G. W. Ott Jr., D. J. Adams, "Harmonic and reactive power compensation based on the generalized instantaneous reactive power theory for three-phase four-wire systems" IEEE Trans. Power Electron., Vol. 13, No. 5, Nov. 1998.

13. V. Soares, P. Verdelho, and G. Marques, "Active power filter control circuit based on the instantaneous active and reactive current id-iq method," IEEE Power Electronics Specialists Conference, Vol. 2, pp 